Review Article

\title{
A Comprehensive Literature Review on the Pandemic Coronavirus Disease 2019 (COVID-19): Bangladesh Is Fighting Against It
}

\author{
Umme Shahera ${ }^{1, ~}$, Nahida Sultana ${ }^{1}$, Mahbuba Sharmin ${ }^{2}$, Jayanta Malakar ${ }^{3}$, \\ Muhammad Rashedul Islam ${ }^{4}$, Kazi Mohammed Zafrul Haq ${ }^{5}$ \\ ${ }^{1}$ Department of Virology, Bangabandhu sheikh Mujib Medical University (BSMMU), Dhaka, Bangladesh \\ ${ }^{2}$ Department of Hematology, Bangabandhu sheikh Mujib Medical University (BSMMU), Dhaka, Bangladesh \\ ${ }^{3}$ Department of Cardiology, Dhaka Medical College Hospital (DMCH), Dhaka, Bangladesh \\ ${ }^{4}$ Director General of Medical Education, Dhaka, Bangladesh \\ ${ }^{5}$ National Institute of Cardiovascular Diseases and Hospital (NICVD), Dhaka, Bangladesh
}

Email address:

sammamjuhaer@yahoo.com (U. Shahera)

${ }^{*}$ Corresponding author

\section{To cite this article:}

Umme Shahera, Nahida Sultana, Mahbuba Sharmin, Jayanta Malakar, Muhammad Rashedul Islam, Kazi Mohammed Zafrul Haq. A Comprehensive Literature Review on the Pandemic Coronavirus Disease 2019 (COVID-19): Bangladesh Is Fighting Against It. American Journal of Biomedical and Life Sciences. Vol. 8, No.4x, 2020, pp. 76-84. doi: 10.11648/j.ajbls.20200804.13

Received: May 29, 2020; Accepted: June 10, 2020; Published: July 6, 2020

\begin{abstract}
A large number of patient developed pneumonia of unknown cause in the capital city Wuhan of Hubei province in China during the month of Dec 2019, with clinical presentations greatly resembling viral pneumonia while some rapidly progressed to severe illness and fatal outcome. International Committee on Taxonomy of Viruses (ICTV) named the virus severe acute respiratory syndrome coronavirus 2 (SARS-CoV-2) and WHO officially named the disease COVID-19. World Health Organization (WHO) on January 30 declared the outbreak as a public health emergency of international concern due to rapid global spread. On 11 February 2020, WHO announced that "COVID-19" (meaning coronavirus disease-2019) will be the official name of the disease. This report reviews the genetic structure, infection source, transmission route, pathogenesis, clinical characteristics, and treatment and prevention of the SARS-CoV-2, so that it can provide references for follow-up research, prevention and treatment, and may help readers to have the latest understanding of this new infectious disease. Information have been gathered mainly from relevant researches and papers that were published recently. For this narrative review, more than 49 relevant scientific articles and reports were considered from various databases (e.g., Google Scholar, PubMed and Science Direct) using keywords such as SARS-CoV-2; COVID-19; corona virus; pneumonia; respiratory infection. The results from this review show that the situation is rapidly evolving, as human-to-human transmission is occurring, and the number of new cases and mortalities is increasing by the day and on a global level. There is still ambiguity about mutation risks and how the virus spreads as the source was not yet identified. Major gaps in knowledge about the origin of the virus, epidemiology and transmission impose a great challenge, which emphasizes the need for further studies in the future. There are neither vaccines nor effective treatments for the disease caused by the virus, but efforts are typically confined to symptomatic and supportive management. Antiviral and corticosteroids were used in severe illness but had no effective outcome.
\end{abstract}

Keywords: SARS-CoV-2, COVID-19, Corona Virus, Pneumonia, Respiratory Infection 


\section{Introduction}

SARS-CoV-2 which was previously known as 2019- nCoV now named by the International Committee on Taxonomy of Viruses is a newly emerging virus affecting the respiratory tract. The disease the virus causes, which was named by the World Health Organization, is coronavirus disease 2019, better known as COVID-19. Given the severe acute respiratory syndrome coronavirus (SARS-CoV) outbreak in 2002 and the Middle East respiratory syndrome coronavirus (MERS-CoV) outbreak in 2012, 2019-nCoV is the third coronavirus to emerge in the human population in the past two decades - an emergence that has put global public health institutions on high alert. [1] Now the infection has been reported in family clusters and medical workers. Also, person to person transmission has been reported. [2] WHO has been deeply concerned by the alarming levels of spread and therefore, made the assessment that COVID- 19 can be characterized as pandemic on 11 March 2020. [3] This paper, focuses on the genetic structures, epidemiology, clinical manifestations, investigations, Control and prevention of the
2019 novel coronavirus infection.

\section{Structure of Coronavirus}

2019-nCoV particles were generally spherical, enveloped with some pleomorphism in electron micrographs, it is about 60 to $140 \mathrm{~nm}$ in diameter. Coronavirus are RNA virus and the virus particles have quite distinctive spikes, about 9 to $12 \mathrm{~nm}$, which give them the appearance of a solar corona. Due to, genetic similarities between the new coronavirus and the coronavirus that caused the SARS outbreak in 2002-2003, recently the new virus has been renamed as SARS-CoV-2. [4] (HCoV-OC43, HCoV-229E, HCoV-NL63, HCoV-HKU1) are the four other human coronaviruses induce mild upper respiratory disease similar to common cold. [5, 6] Previously emerged the two highly pathogenic viruses, the severe acute respiratory syndrome coronavirus (SARS-CoV) and the Middle East respiratory syndrome coronavirus (MERS-CoV) cause more severe, pneumonia like symptoms, severe acute respiratory syndrome (SARS) and sometimes fatality in humans. [7-9]

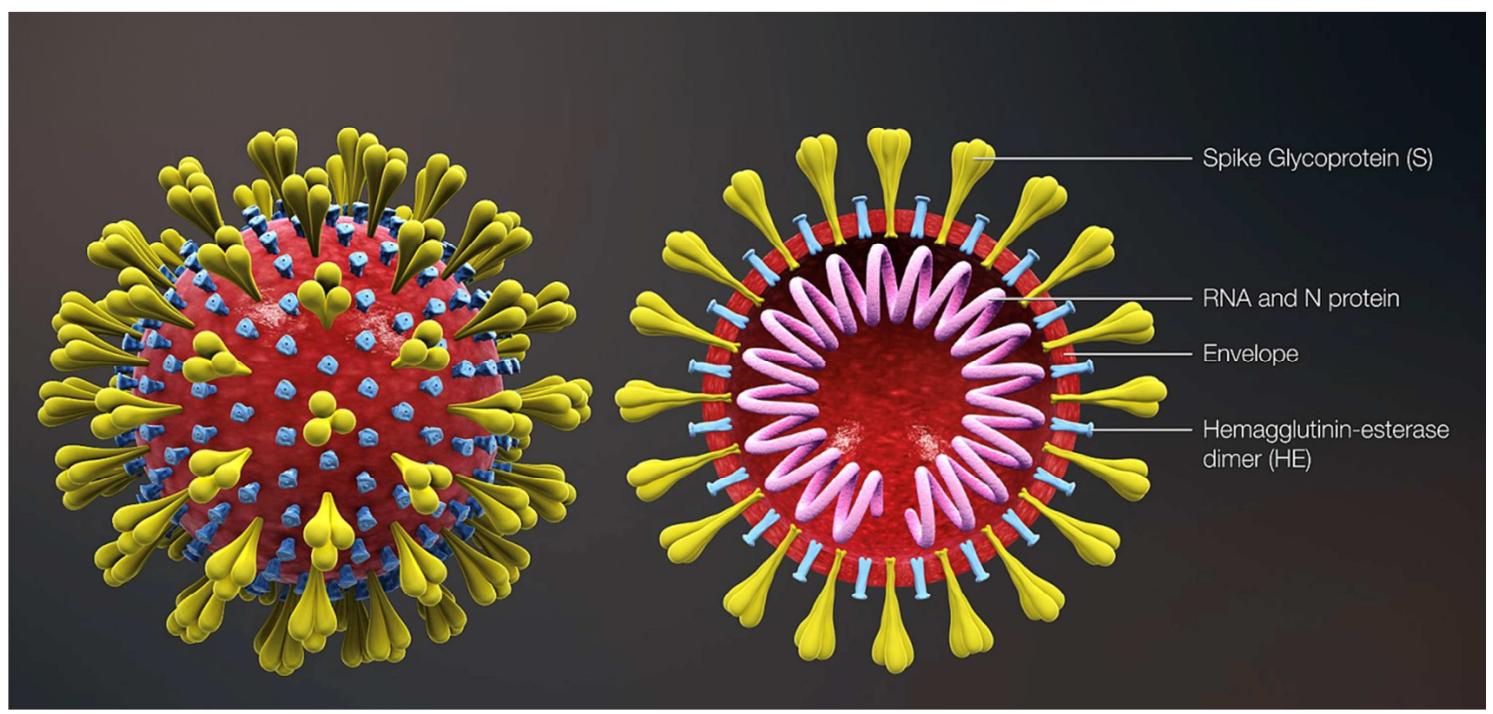

Figure 1. Structure of Coronavirus.

\section{Epidemiology of Coronavirus}

Coronaviruses are distributed widely in many varieties species of animals, including bats, cattle, cats, birds, and camels. [10] In 1960 the first case of human coronavirus $(\mathrm{HCoV})$ infection was reported in a patient with common cold. Since then, coronaviruses have been simultaneously maintained in nature and caused fatal human respiratory diseases worldwide. Coronaviruses infect different domestic and wild animals, as well as humans and cause diseases in them. The natural reservoir host of coronaviruses is bat. The alpha- and beta-coronaviruses mainly infect mammals, while gamma and delta-coronaviruses mainly infect birds. Since 2002, beta-coronaviruses, MERS-CoV and SARS-CoV have caused pandemics in human. [11]

Bats have been recognized to harbor the viruses of
SARS-CoV, MERS-CoV, and now the 2019-nCoV. Majority of the coronaviruses can be found in China because most of these bat hosts live near humans, which potentially transmit viruses to livestock and humans. Several facts suggest that the 2019-nCoV is transmitted to humans via an intermediate host, between bats and humans. And the humans act as terminal hosts. It is because when the epidemic was first reported in Wuhan in December 2019, most of the bat species were hibernating and no bats were being sold or found at the Huanan seafood market; however, various non-aquatic animals (including mammals) were being sold. Snakes might be the wildlife animal reservoir, which acted as intermediate host for the 2019-nCoV. However, it is not yet confirmed that which wildlife animal is exactly responsible for transmitting 2019- nCoV to humans, and further investigations are still required. [2] 


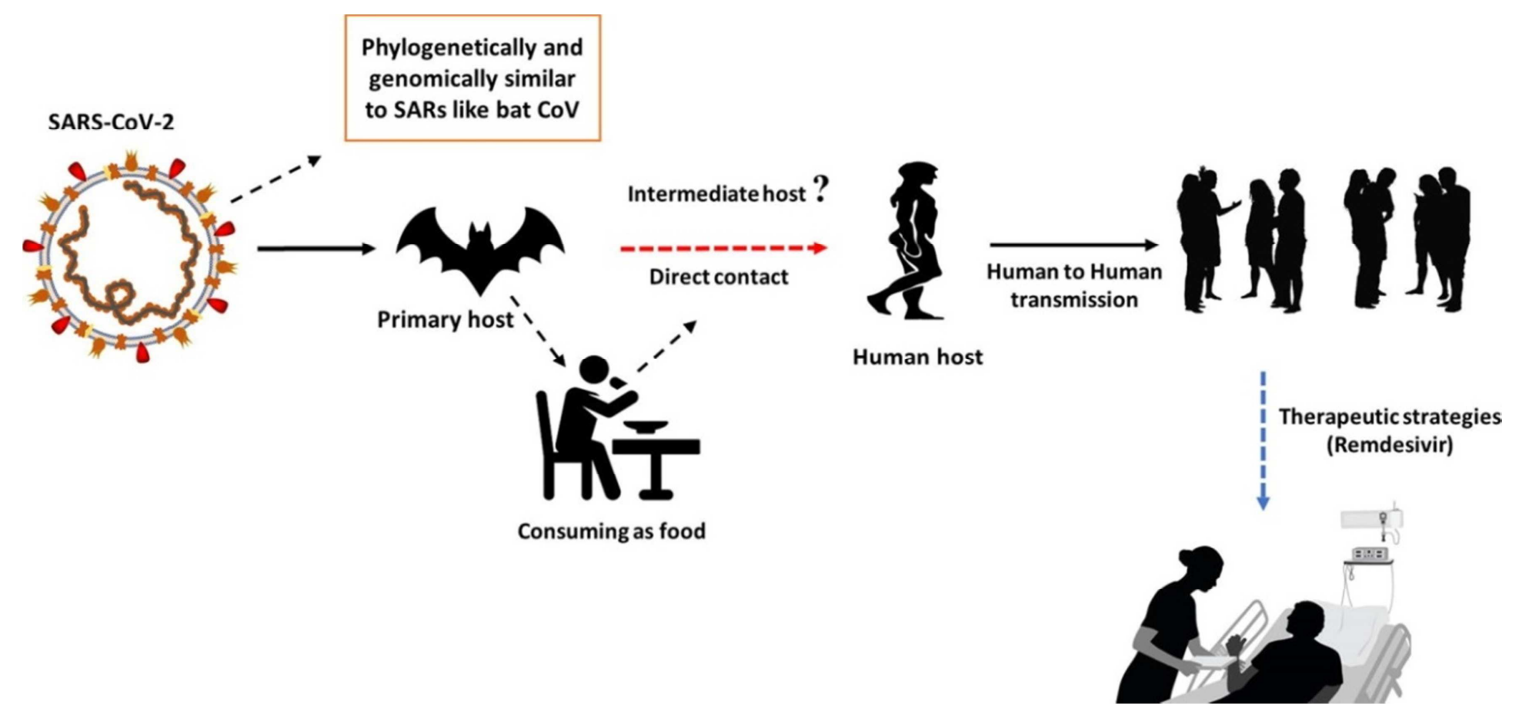

Figure 2. Epidemiology of Covid-19.

\section{Route of Transmission}

Close contact are the most common ways of transmission for SARS-CoV-2. Aerosol transmission might also be a way of transmission. Researchers also detected SARS-CoV-2 in the samples of stool, gastrointestinal tract, saliva and urine. Digestive tract might be a potential route of SARS-CoV-2 infection based on bioinformatics evidence. [12] Consistently, SARS-CoV-2 RNA was also dectected in gastrointestinal tissues from COVID-19 patients. [13] SARS-CoV-2 was also detected in the tears and conjunctival secretions of covid-19 patients. [14] A retrospective study based nine pregnant women with COVID-19 had for the first time indicated that the possibility of intrauterine vertical transmission between mothers and infants in the late pregnancy was temporarily excluded. [15] However, available data on pregnant women infected with SARS-CoV-2 were inadequate, and hence further studies are required to verify the potential vertical transmission of SARS-CoV-2 in pregnant women.

\section{Pathogenesis}

SARS-CoV-2's and SARS-CoV share similarities in physical structure and pathogenic behavior. A protein called a spike (S) protein to bind to target cells and a cellular protease to prime the $\mathrm{S}$ protein is present in $\mathrm{CoV}$. "There is a similarity in sequence around $76 \%-78 \%$ for the whole protein, around $73 \%-76 \%$ for the RBD [receptor binding domain], and $50 \%-53 \%$ for the RBM [receptor binding motif] [16]. The target cellular receptor for the S protein of SARS-CoV-2 was the same as SARS-CoV, angiotensin-convertingenzyme 2 (ACE2). The cellular protease, TMPRSS2, was the similarities. [16-18] Though there is many similarities between SARS-CoV-2 and SARS-CoV, SARS-CoV-2 is more closely related to two other coronaviruses found in bats, bat-SL-CoVZC45, and bat-SL-CoVZXC21 [16], which proves that bats are the reservoir for this virus [19].
The pathophysiology of high pathogenicity for 2019-nCoV has not been completely understood. The lower respiratory tract is the main target of COVID-19 infection causing severe pneumonia, combined with radiologic evidences of ground-glass opacities. [20, 21] Significantly high blood levels of proinflammatory cytokines and chemokines were noted in patients with COVID-19 infection. [17, 20-21] Chen et al. have postulated that virus particles spread through the respiratory mucosa and infect other cells, induce a cytokine storm in the body, generate a series of immune responses, and cause changes in peripheral white blood cells such as lymphocytes that have role in body immune response. They found that some patients progressed rapidly with acute respiratory distress syndrome (ARDS) and septic shock, which was eventually followed by multiple organ failure. The most common laboratory abnormality observed was decreased count of total lymphocytes. A substantial decrease in the total number of lymphocytes indicates that coronavirus consumes many immune cells and inhibits the body's cellular immune function. The study also observed elevated lactate dehydrogenase and prolonged prothrombin time. ${ }^{17}$ Based on these abnormalities 2019- nCoV infection may be associated with cellular immune deficiency, coagulation activation, myocardial injury, hepatic injury, and kidney injury based on these abnormalities. Other studies have also observed similar decrease in total lymphocyte count in most patients with COVID-19. [20, 22]

\section{Clinical Characteristics}

While the incubation period of the virus was initially thought to be 14 days, multiple cases have been reported with shorter timelines. A study by Guan et al. calculated the median incubation period to be four days with a lower interquartile range of two days and an upper interquartile range of seven days. In their study, the most common finding on imaging was ground-glass opacity on CT $(56.4 \%)$. [23] They found that $43.8 \%$ had a fever on admission and $88.7 \%$ during 
hospitalization. The cough was also a common symptom and was seen in $67.8 \%$ of patients. The Chinese Center for Disease Control and Prevention has reported that $87 \%$ of confirmed cases were in adults aged between 30 and 79 years. The mortality and case fatality rate increased with increasing ages; the case fatality rate was $8 \%$ in patients aged between 70 and 79 years while it was $15 \%$ in those aged 80 years or more. [24]

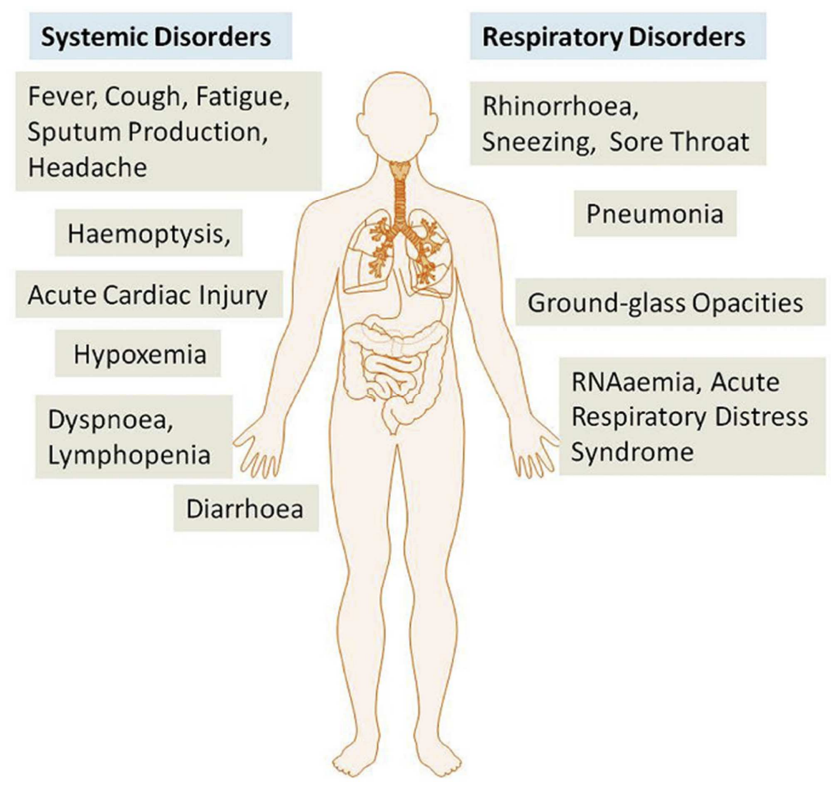

Figure 3. Clinical features of Covid-19.

Common symptoms at onset of illness were fever, dry cough, dyspnoea, fatigue, myalgia, and anorexia. Less common symptoms were headache, sore throat, rhinorrhoea, dizziness, abdominal pain, diarrhea, nausea, vomiting and confusion. WHO has recently classified 6 clinical syndromes associated with SARS-CoV-19 infection: uncomplicated illness, mild pneumonia, severe pneumonia, ARDS, sepsis and septic shock. In uncomplicated illness, the affected persons may have non-specific symptoms such as fever, cough, sore throat, nasal congestion, malaise, headache, muscle pain or malaise. Patient with mild pneumonia have no signs of severe pneumonia. In severe pneumonia patients have fever or suspected respiratory infection, plus one of respiratory rate $>30$ breaths/min, severe respiratory distress, or oxygen saturation $<90 \%$ on room air. ARDS patients have worsening respiratory symptoms with chest imaging evidence of bilateral opacities. In sepsis, adults have life-threatening organ dysfunction. Adult patients with septic shock have persistent hypotension despite volume resuscitation, requires vasopressors to maintain mean arterial pressure $\geq 65 \mathrm{mmHg}$ and serum lactate level $>2 \mathrm{mmol} / \mathrm{L}$. [25]

\section{Diagnosis}

During the outbreak, the presence of 2019-nCoV RNA in respiratory specimens (nasal swab, throat swab, bronchial aspirates) was confirmed by real-time RT-PCR assay. [6, 20, 21] Imaging (chest $x$-ray/CT scan) showed bilateral patchy shadows or ground glass opacity in the lungs of all the admitted patients having pneumonia.

IgM and IgG ELISA detection kits using bat SARSr-CoV Rp3 NP were developed with no cross-reaction against human coronaviruses except SARSr-CoV. [26] The procedures of ELISA for the determination of SARS-CoV-2 IgG were described before. [27] Nucleic acid detection is the main, fastest, and most sensitive test for the diagnosis of SARS-CoV-2 infection. Recently, two nested RT-PCR and two real-time RT-PCR assays have been developed with successful detection of the first 25 positive cases of infection in Japan. [28] Three real-time RT-PCR techniques have been designed based on the $\mathrm{E}, \mathrm{RdRp}$, and $\mathrm{N}$ genes. [29] Also, scientists established molecular detection tools for SARS-CoV-2 based on the S gene. [27]

Complete blood counts revealed lymphocytopenia in most of the hospitalized cases. Lymphocytopenia occurred in $70.3 \%$, of hospitalized 138 patients in a study carried out by Wang et al. [22] and non-survivors developed more severe lymphocytopenia over time. On admission, Wei-Jie et al. found, lymphocytopenia in $83.2 \%$ of the patients, thrombocytopenia in $36.2 \%$, and leukopenia in $33.7 \%$. [30]

\section{Treatment and Prevention}

Until now, no specific treatment has been recommended for this emerging coronavirus infection except for meticulous supportive care. [31] Antiviral treatment for 2019-nCoV infection has not been proven to be effective. All patients need to be treated in isolation. Currently, as described, the approach to this disease is to control the source of infection; use of personal protection precaution to reduce the risk of transmission; and early diagnosis, isolation, and supportive treatments for affected patients. [22]

At present, there is no vaccine or effective antiviral treatment for coronavirus. Trials with a considerable number of investigational agents like lopinavir, ritonavir, remdesivir, nelfinavir, interferon beta, chloroquine, some of them were suggested that they may be effective for treating the 2019-nCoV; even that, the efficacy and long term safety of those drugs still need to be further confirmed by clinical experiments. [25, 32-24] According to WHO the best prevention measure is cleaning of hands with soap and water or using alcohol based hand wash very frequently. [35] As a precautionary measure frequent touching the face, mouth, eyes and nose should be avoided.

People can take several steps, including:

1. Resting and avoiding overexertion

2. Drinking enough water

3. avoiding smoking and smoky areas

4. Taking acetaminophen, ibuprofen, or naproxen for pain and fever

5. Using a clean humidifier or cool mist vaporizer

6. A doctor can diagnose the virus responsible by taking a sample of respiratory fluids, such as mucus from the nose, or blood.

7. Standard recommendations to prevent infection spread. 


\section{COVID-19 Pandemic in Bangladesh and Our Preparedness}

The COVID-19 pandemic was confirmed to have spread to Bangladesh on March 2020. The first three known cases were reported on 7 March 2020 by the country's epidemiology institute IEDCR. [36] Infections stayed low till the end of March but saw a steep rise in April. [37] In the week ending 11 April, new cases in Bangladesh grew 1,155 percent, the highest in Asia, ahead of Indonesia with 186 percent. [38] As of 5 May 2020, there are a total of 10,929 confirmed cases besides 1,403 recovered \& 183 deaths in the country. [39] For a long time, testing was centralized to only Institute of Epidemiology, Disease Control and Research (IEDCR) in the capital Dhaka, although patients with symptoms were reported all around the country. On 22 January, the authorities at the Dhaka airport put the airports on alert by screening travelers from China. [40-41] On 1 February, a special flight from Bangladesh evacuated 312 Bangladeshi citizens stranded in Wuhan. [42] The evacuees were quarantined for 14 days at the Ashkona Hajj Camp in Dhaka and other locations. [43-44] None of them tested positive for the coronavirus. [45-46] On 8 March, the first three coronavirus cases were confirmed. [36] They included two men that recently returned from Italy and a female relative. [47] Bangladesh has 1,169 ICU beds, amounting to 0.72 beds per 100,000 citizens. Of these 432 beds are in government hospitals and 737 in private hospitals. [49] There are only 550 ventilators in the country. [49] On 21 March, the IEDCR announced that 150 ICU beds would be made available for COVID treatment in Dhaka and more would be provided in other parts of Bangladesh. [48] By 8 April, it was reported that 112 ICU beds were available, of which 79 were in Dhaka, 26 in Mymensingh, 5 in Khulna and 2 in Sylhet. The government was in the process of procuring
380 ventilators. [49] Till now 60 laboratories are doing the tests all over the country.

Data of Bangladesh

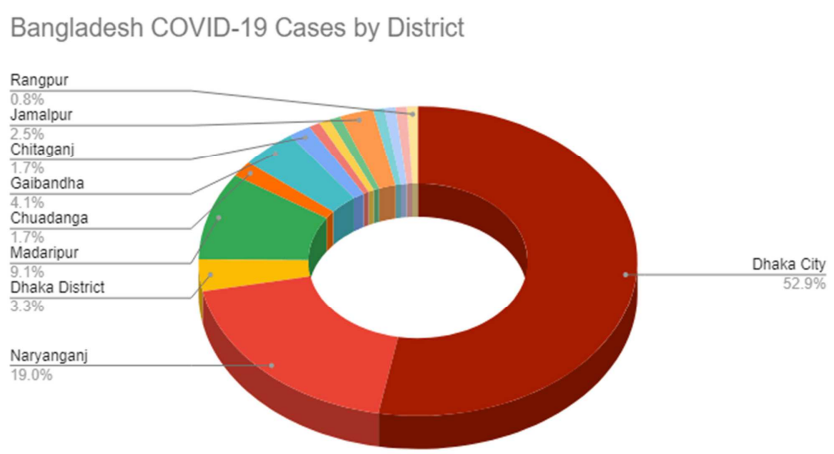

Figure 4. Covid-19 cases distribution among districts of Bangladesh (source: bdnewsnet.com).

Young and working-age people have been infected most with the COVID-19 virus in Bangladesh.

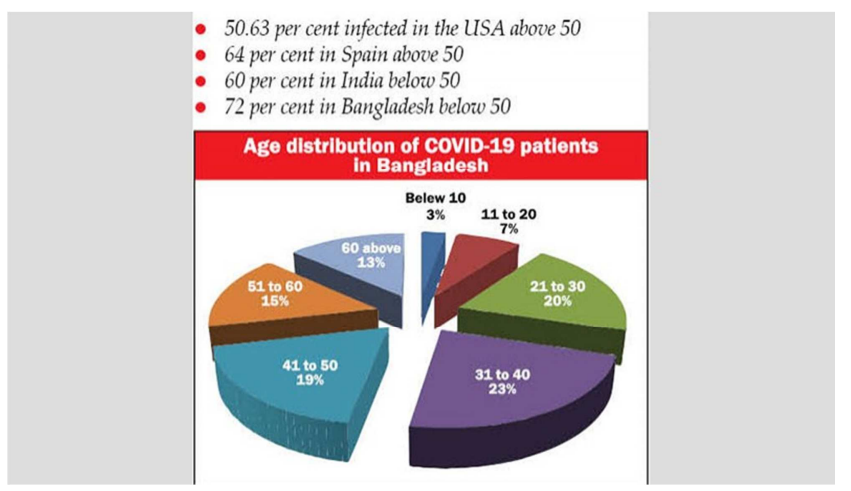

Figure 5. Age distribution of Covid-19 in Bangladeshi population.

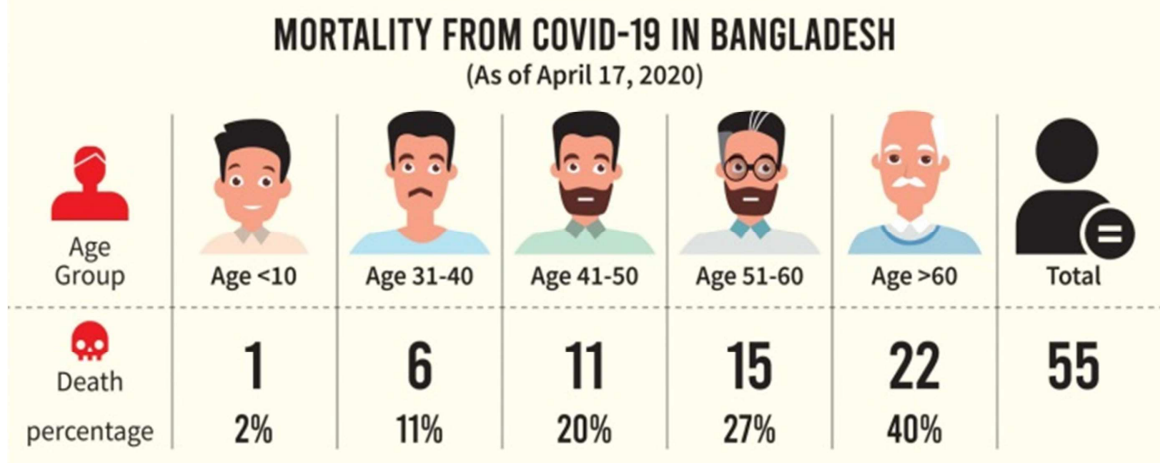

Figure 6. Mortality from Covid-19 in Bangladesh (source: tbsnews.net).

Unlike the mortality trend in other countries, death from coronavirus infection in Bangladesh presents a unique case, available data show. While the elderly are mostly dying from the virus around the world, it is less discriminating in Bangladesh.

The dead include a wide cross section of the population. There are children in the list of dead. There are relatively younger persons among the dead as well, who are expected to have stronger immune systems. There are higher fatalities among the elder lies and socio-economic background does not seem to be a factor as to who will survive. In other words, everyone is being affected by the disease.

Between 8 March and 28 June 2020, according to the Institute of Epidemiology, Disease Control and Research (IEDCR), there were one-lac-thirty-seven-thousand and seven- hundred-eighty-seven $(137,787)$ COVID-19 confirmed by rt-PCR, including one-thousand and seven-hundred-thirty-eight $(1,738)$ related death cases (CFR 
$1.26 \%)$. Seventy-two (72\%) of all confirmed cases were males.

\section{Conclusion}

With the emergence of the 2019 novel corona virus (SARS-CoV-2), the knowledge of its epidemiology, infectivity rate, clinical manifestations, treatment and mortality rates is also in the development process and the full spectrum of the disease will be understood soon. The disease is more likely to occur in older people with co-morbidities, and can result in severe and even fatal respiratory diseases. Till now there is no effective specific therapy, but supportive managements are given. Researches and trials are going on with investigational agents for the effective management of the disease. Prevention measures are implemented globally, and investigations are ongoing to find the source of the disease and to understand more about the virus's characteristics, illness severity, and transmission routes. Major gaps are presented as the majority of what we know about the virus is based on similar corona viruses, but the work on treatment is promising. In order to have a better understanding of the new virus, countries should work on providing reliable data through openness and data sharing, as well as conducting further researches on the reported cases. In addition, countries should keep working on improving the preventive measures implemented to reduce the number of infected patients and transmissions at the same time. The SARS-CoV-2 is spreading across the world at an alarming rate. The elderly and immunocompromised patients are most vulnerable to the mortal repercussions of the virus.

While some treatment protocols have shown some promise, there is at present no confirmed cure for the virus and no vaccine has been developed. With proper preventive measures, the virus can be contained and the population protected.

\section{References}

[1] Regan H, Renton A, John T (2020) Global death toll rises to 2, 458 as Hubei province in China reports more deaths. CNN.

[2] Lu, R., Zhao, X., Li, J., Niu, P., Yang, B., Wu, H., Tan, W. (2020). Genomic characterization and epidemiology of 2019 novel corona virus: implications for virus origins and receptor binding. Lancet (London, England), 6736 (20), 1-10.

[3] World Health Organization. Corona virus disease 2019 (COVID-19) Situation Report-51. Data as reported by national authorities by 10 AM CET 11 March 2020.

[4] Gorbalenya, Alexander E. Severe acute respiratory syndrome-related corona virus -The species and its viruses, a statement of the Coronavirus Study Group. Posted on 11 February 2020.

[5] Su S, Wong G, Shi W, Liu J, Lai ACK, Zhou J, et al. Epidemiology, genetic recombination, and pathogenesis of corona viruses. Trends Microbiol. 2016; 24 (6): 490-502.

[6] Chen N, Zhou M, Dong X, Qu J, Gong F, Han Y, et al. Epidemiological and clinical characteristics of 99 cases of 2019 novel corona virus pneumonia in Wuhan, China: A descriptive study. Lancet. 2020; 395 (10223): 507-513.

[7] Cui J, Li F, Shi ZL. Origin and evolution of pathogenic corona viruses. Nat Rev Microbial. 2019; 17: 181-192.

[8] Zhong NS, Zheng BJ, Li YM, Poon, Xie ZH, Chan KH, et al. Epidemiology and cause of severe acute respiratory syndrome (SARS) in Guangdong, People's Republic of China, in February, 2003. Lancet. 2003; 362 (9393): 1353-1358.

[9] Ksiazek TG, Erdman D, Goldsmith CS, Zaki SR, Peret T, Emery $\mathrm{S}$, et al. A novel coronavirus associated with severe acute respiratory syndrome. N Engl J Med. 2003; 348; 1953-1966.

[10] Weiss SR, Leibowitz JL. Corona virus pathogenesis. Adv Virus Res. 2011; 81: 85-164.

[11] Zaki, A. M., Van Boheemen, S., Bestebroer, T. M., Osterhaus, A. D. M. E., \& Fouchier, R. A. M. (2012). Isolation of a novel corona virus from a man with pneumonia in Saudi Arabia. New England Journal of Medicine.

[12] Wang J, Zhao S, Liu M, Zhao Z, Xu Y, Wang P, et al. ACE2 expression by colonic epithelial cells is associated with viral infection, immunity and energy metabolism. 2020: 2020.02.05.20020545.

[13] Xiao F, Tang M, Zheng X, Li C, He J, Hong Z, et al. Evidence for gastrointestinal infection of SARS-CoV-2. medRxiv. 2020: 2020.02.17.20023721.

[14] Xia J, Tong J, Liu M, Shen Y, Guo D. Evaluation of coronavirus in tears and conjunctival secretions of patients with SARS-CoV-2 infection. Journal of medical virology. 2020.

[15] Chen H, Guo J, Wang C, Luo F, Yu X, Zhang W, et al. Clinical characteristics and intrauterine vertical transmission potential of COVID-19 infection in nine pregnant women: a retrospective review of medical records. The Lancet. 2020.

[16] Wan Y, Jian Shang, Rachel Graham, Ralph S Baric, Fang Li (2020) Receptor recognition by a novel coronavirus from Wuhan: An analysis based on decade-long structural studies of SARS. J Virol.

[17] Lu R, Xiang Zhao, Juan Li, Peihua Niu, Bo Yang, et al. (2020) Genomic characterization and epidemiology of 2019 novel coronavirus: implications for virus origins and receptor binding. The Lancet 395 (10224): 565-574.

[18] Hoffmann M, Hannah Kleine Weber, Nadine Krüger, Marcel Müller, Christian Drosten, et al. (2020) The novel coronavirus 2019 (2019- $\mathrm{nCoV}$ ) uses the SARS-coronavirus receptor ACE2 and the cellular protease TMPRSS2 for entry into target cells. bioRxiv.

[19] Wang D, Bo $\mathrm{Hu}$, Chang $\mathrm{Hu}$, et al. (2020) Clinical Characteristics of 138 Hospitalized Patients With 2019 Novel Coronavirus-Infected Pneumonia in Wuhan, China. JAMA.

[20] Huang C, Wang Y, Li X, Ren L, Zhao J, Hu Y, et al. Clinical feature of patients infected with 2019 novel coronavirus in Wuhan, China. Lancet. 2020; 395 (10223): 497-506. Published online on 24 Jan 2020.

[21] Rothan HA, Byrareddy SN. The epidemiology and pathogenesis of coronavirus disease (COVID-19) outbreak. Journal of Autoimmunity. Published online on 26 Feb, 2020. 
[22] Wang D, Hu B, Hu C, Zhu F, Liu X, Zhang J, et al. Clinical Characteristics of 138 Hospitalized Patients with 2019 Novel Coronavirus-Infected Pneumonia in Wuhan, China. JAMA. Published online on 07 Feb, 2020.

[23] Guan WJ, Ni ZY, Hu Y, et al.: Clinical characteristics of coronavirus disease 2019 in China. N Engl J Med. 2020, 10.1056/NEJMoa2002032.

[24] Wu Z, McGoogan JM: Characteristics of and important lessons from the coronavirus disease 2019 (COVID-19) outbreak in China: summary of a report of 72314 cases from the Chinese Center for Disease Control and Prevention. JAMA. 2020, 10.1001/jama.2020.2648.

[25] World Health Organization. Clinical management of severe acute respiratory infection when novel coronavirus (nCoV) infection is suspected: interim guidance; $28 \mathrm{Jan}, 2020$.

[26] Chen, Z. M.; Fu, J. F.; Shu, Q.; Chen, Y. H.; Hua, C. Z.; Li, F. B.; Lin, R.; Tang, L. F.; Wang, T. L.; Wang, W.; et al. Diagnosis and treatment recommendations for pediatric respiratory infection caused by the 2019 novel coronavirus. World J. Pediatr. 2020. [CrossRef].

[27] Zhang, W.; Du, R.-H.; Li, B.; Zheng, X.-S.; Yang, X.-L.; Hu, B.; Wang, Y.-Y.; Xiao, G.-F.; Yan, B.; Shi, Z.-L. Molecular and serological investigation of $2019-\mathrm{nCoV}$ infected patients: Implication of multiple shedding routes. Emerg. Microbes Infect. 2020, 9, 386-389. [CrossRef] [PubMed].

[28] Shirato, K.; Nao, N.; Katano, H.; Takayama, I.; Saito, S.; Kato, F.; Katoh, H.; Sakata, M.; Nakatsu, Y.; Mori, Y.; et al. Development of genetic diagnostic methods for novel coronavirus 2019 (nCoV-2019) in Japan. Jpn. J. Infect. Dis. 2020, in press. [CrossRef] [PubMed].

[29] Corman, V. M.; Landt, O.; Kaiser, M.; Molenkamp, R.; Meijer, A.; Chu, D. K. W.; Bleicker, T.; Brunink, S.; Schneider, J.; Schmidt, M. L.; et al. Detection of 2019 novel coronavirus (2019-nCoV) by real-time RT-PCR. Euro. Surveill. 2020, 25, 2000045. [CrossRef] [PubMed].

[30] Wei-Jie G, Zheng-Yi N, Yu Hu, Wen-Hua L, Chun-Quan O, Jian-Xing $\mathrm{H}$, et al. Clinical characteristics of coronavirus disease 2019 in China. NEJM. Published online on $28 \mathrm{Feb}$, 2020 .

[31] De Wit E, van Doremalen N, Falzarano D, Munster VJ. SARS and MERS: Recent insights into emerging coronaviruses. Nat Rev Microbiol. 2016; 14: 523-534.

[32] Lu H. Drug treatment options for the 2019- new coronavirus (2019-nCoV). Biosci Trends. Published online on 28 Jan 2020.

[33] Wang M, Cao R, Zhang L, Yang X, Liu J, Xu M, et al. Remdesivir and chloroquine effectively inhibit the recently emerged novel coronavirus (2019-nCoV) in vitro. Cell Res. 4 Feb, 2020.
[34] Zhijian X, Cheng P, Yulong S, Zhengdan Z, Kaijie M, Xiaoyu Wang, et al. Nelfinavir was predicted to be a potential inhibitor of 2019 nCov main protease by an integrative approach combining homology modelling, molecular docking and binding free energy calculation. Posted on: 28 Jan, 2020.

[35] World Health Organization, 2020. Coronavirus disease (COVID-19) advice for the public. Available: https://www.who.int/emergencies/diseases/novel-coronavirus2019/advicefor-public/when-and-how-to-use-masks.

[36] "Bangladesh confirms its first three cases of coronavirus". Reuters. 8 March 2020. Archived from the original on 27 March 2020. Retrieved 27 March 2020.

[37] 20-fold rise in Covid-19 cases in Bangladesh since April 1, Dhaka Tribune, 14 April 2020.

[38] Mint Covid Tracker: India's corona trajectory has tapered this week but still remains steeper than Asian peers, livemint, 11 April 2020.

[39] Research (IEDCR), Institute of Epidemiology, Disease Control and. "Corona info". corona.gov.bd. Retrieved 3 May 2020.

[40] "Screening starts at Dhaka, Ctg airports". Screening starts at Dhaka, Ctg airports | theindependentbd.com. Archived from the original on 28 March 2020. Retrieved 28 March 2020.

[41] "Virus prompts temperature checks, extra cleaning at airports". ABC News. Retrieved 28 March 2020.

[42] "Government sends plane today to fly back citizens". New Age. Archived from the original on 28 March 2020. Retrieved 28 March 2020.

[43] "312 Bangladeshis quarantined in Dhaka after arriving from Wuhan". New Age. Archived from the original on 28 March 2020. Retrieved 28 March 2020.

[44] "Govt brings 361 back from Wuhan early Saturday". New Age. Archived from the original on 28 March 2020. Retrieved 28 March 2020.

[45] "Expats asked to call IEDCR if in difficulties". New Age. Retrieved 28 March 2020

[46] "23 Bangladeshis flown to Delhi from Wuhan". New Age. Archived from the original on 28 March 2020. Retrieved 28 March 2020.

[47] "IEDCR asks returnees from virus-affected countries to avoid public transport". The Daily Star. 8 March 2020. Archived from the original on 9 April 2020. Retrieved 8 April 2020.

[48] Mamun Abdullah, Number of ICU beds insufficient to combat Covid-19 pandemic, Dhaka Tribune, 21 March 2020.

[49] Bangladesh may suffer setback in its fight against corona virus for shortage of life-saving ventilators: Physicians, UNB (United News of Bangladesh), 10 April 2020. 